\title{
Benzene exposure at workplace and risk of colorectal cancer in four Nordic countries
}

\section{Talibov, Madar}

2018-08

Talibov , M , Sormunen , J , Hansen , J , Kjaerheim , K, Martinsen , J-I , Sparen , P , Tryggvadottir , L , Weiderpass , E \& Pukkala , E 2018, ' Benzene exposure at workplace and risk of colorectal cancer in four Nordic countries ', Cancer Epidemiology, vol. 55 , pp. 156-161 . https://doi.org/10.1016/j.canep.2018.06.011

http://hdl.handle.net/10138/305071

https://doi.org/10.1016/j.canep.2018.06.011

publishedVersion

Downloaded from Helda, University of Helsinki institutional repository.

This is an electronic reprint of the original article.

This reprint may differ from the original in pagination and typographic detail.

Please cite the original version. 


\title{
Benzene exposure at workplace and risk of colorectal cancer in four Nordic countries
}

\author{
Madar Talibov $^{\mathrm{a}, \mathrm{b}, *}$, Jorma Sormunen ${ }^{\mathrm{a}, \mathrm{c}}$, Johnni Hansen ${ }^{\mathrm{d}}$, Kristina Kjaerheim ${ }^{\mathrm{e}}$, \\ Jan-Ivar Martinsen ${ }^{\mathrm{e}}$, Per Sparen ${ }^{\mathrm{f}}$, Laufey Tryggvadottir ${ }^{\mathrm{g}, \mathrm{h}}$, Elisabete Weiderpass ${ }^{\mathrm{f}, \mathrm{i}, \mathrm{j}, \mathrm{k}}$, \\ Eero Pukkala ${ }^{\mathrm{a}, \mathrm{l}}$

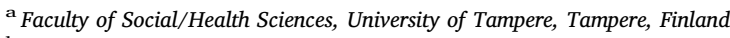 \\ ${ }^{\mathrm{b}}$ International Agency for Research on Cancer, Environment and Radiation Section, Lyon, France \\ c Tampere University Hospital, Department of Oncology, Tampere, Finland \\ d The Danish Cancer Society Research Center, Copenhagen, Denmark \\ e Cancer Registry of Norway, Oslo, Norway \\ ${ }^{\mathrm{f}}$ Department of Medical Epidemiology and Biostatistics, Karolinska Institutet, Stockholm, Sweden \\ ${ }^{\mathrm{g}}$ Icelandic Cancer Registry, Reykjavik, Iceland \\ ${ }^{\mathrm{h}}$ Faculty of Medicine, University of Iceland, Reykjavik, Iceland \\ ${ }^{i}$ Department of Community Medicine, Faculty of Health Sciences, University of Tromsø, The Arctic University of Norway, Tromsø, Norway \\ ${ }^{\mathbf{j}}$ Department of Research, Cancer Registry of Norway, Institute of Population-Based Cancer Research, Oslo, Norway \\ ${ }^{\mathrm{k}}$ Genetic Epidemiology Group, Folkhälsan Research Center, Faculty of Medicine, University of Helsinki, Helsinki, Finland \\ ${ }^{1}$ Finnish Cancer Registry, Institute for Statistical and Epidemiological Cancer Research, Helsinki, Finland
}

\section{A R T I C L E I N F O}

\section{Keywords:}

Benzene

Occupation

Colorectal cancer

Case-control study

\begin{abstract}
A B S T R A C T
Objective: The aim of this case-control study was to assess the effect of occupational benzene exposure on the risk of colorectal cancer, including its subtypes.

Methods: The study included 181,709 colon cancer and 109,227 rectal cancer cases diagnosed between 1961 and 2005 in Finland, Iceland, Norway and Sweden. Cases were identified from the Nordic Occupational Cancer Study (NOCCA) cohort. Five controls per case were selected from the same cohort, matched for country, birth year, and sex. Occupational benzene exposure for each study participant was estimated by linking their job titles to country specific job-exposure matrices. Odds ratios (OR) and 95\% confidence intervals (CI) were calculated by using conditional logistic regression models. The results were adjusted for physical strain at work, formaldehyde, ionizing radiation and wood dust.

Results: Increased risk was observed for all colorectal cancer (OR = 1.12, 95\% CI 1.05-1.18) for the high decile of cumulative benzene exposure, indicating a statistically significant dose-response relationship. This excess risk was mainly seen in ascending colon (OR $=1.27,95 \% \mathrm{CI} 1.13-1.43)$, and transversal colon $(\mathrm{OR}=1.21$, 95\% CI 1.01-1.41). The ORs in the highest exposure category were markedly higher in women than in men in all subsites of colon and rectum.

Conclusion: This study showed an association between workplace benzene exposure and colorectal cancer. The risk was restricted to ascending and transversal colon, and was the strongest among women.
\end{abstract}

\section{Background}

Benzene exposure at workplace has historically occurred via inhalation or dermal absorption of solvents, especially in the rubber, paint, printing and parts-manufacturing industries. It may also occur during chemical manufacturing and crude oil refining. Workers involved in transportation of crude oil and gasoline, dispensing of gasoline at service stations are also occupationally exposed to benzene. Drivers experience benzene exposure due to exhaust fumes from motor vehicles [1].

Benzene has been classified as a Group 1 carcinogen by the International Agency for Research on Cancer since 1979, based on

\footnotetext{
* Corresponding author at: Faculty of Social/Health Sciences, University of Tampere, Tampere, Finland.

E-mail addresses: Mader.Talibov@gmail.com (M. Talibov), Jorma.Sormunen@gmail.com (J. Sormunen), johnni@cancer.dk (J. Hansen), kristina.kjaerheim@kreftregisteret.no (K. Kjaerheim), Jan.Ivar.Martinsen@kreftregisteret.no (J.-I. Martinsen), par.sparen@ki.se (P. Sparen), laufeyt@krabb.is (L. Tryggvadottir), elisabete.weiderpass@kreftregisteret.no (E. Weiderpass), eero.pukkala@cancer.fi (E. Pukkala).
} 
studies of leukemia [2]. This evaluation was reaffirmed specifically for acute myeloid leukemia and acute non-lymphocytic leukemia in 2009 [3], as well as in 2017 [4]. More recently, there have been numerous reports for benzene exposure and leukemia subtypes, non-Hodgkin lymphoma, multiple myeloma, and to a lesser extent other tumors in adults [5-7].

Colorectal cancer is the third most commonly diagnosed malignancy and the fourth leading cause of cancer death in the world, with more than two-thirds of all cases and about $60 \%$ of all deaths occurring in countries with a high or very high human development index [8]. The incidence rates of colorectal cancers has increased in the Nordic countries over the past decades [9].

Lifestyle factors such as obesity, lack of physical activity, smoking, alcohol intake, and consumption of red and processed meat have been linked to an increased risk of colorectal cancers [10-14].

Among occupational factors, a protective effect on the risk of colon cancer was observed for physical activity at workplace in some previous studies [15-17]. Increased risk of colorectal and rectal cancers, but not colon cancer, was reported for diesel exhaust exposure in Canadian men [18]. Prolonged exposure to asbestos was linked to an elevated risk of cancer of total colon, distal colon and rectum in the Prospective Netherlands Study [19]. Some recent studies of night shift-work have also been associated with colorectal cancer [20]. Potential associations for other occupational agents were also suggested [21,22]. However, colorectal cancer was not linked to selected solvents, combustion products, metals, dusts and other occupational agents in a recent casecontrol study [23].

Evidence on association between benzene exposure and colorectal cancer is very limited and inconsistent. Increased incidence of cancer of colon and rectum was observed in a study of Danish seafarers exposed to substances including benzene [24], and Goldberg et al [25] observed some evidence for association between benzene and colon cancer. However, no association between benzene exposure and cancers of colon and rectum was found in a case-control study in Montreal, Canada [26].

The aim of the current study was to assess the effect of occupational benzene exposure on the risk of colorectal cancer, including its subtypes.

\section{Methods}

The current case-control study was nested within the Nordic Occupational Cancer Study (NOCCA) cohort. The NOCCA cohort consists of 14.9 million persons from Finland, Iceland, Norway, Sweden and Denmark [27], and it is based on a linkage between national census records and cancer registries. Persons were included into the cohort on January 1 of the year following the first available census where they participated, provided they were 30-64 years old. They were then followed up till the date of emigration, death or December 31 of the following years: in Denmark 2003, in Finland 2005, in Iceland 2004, in Norway 2003, and in Sweden 2005 [27]. Information on dates of death and emigration was obtained from Central Population Registers of these countries. Data from various registries were linked by using unique personal identification numbers used in all five Nordic countries. This method ensured a complete ascertainment of relevant events for each person included into the cohort, because the possibility of error in identifiers is extremely small [27]. Data from Denmark were not included in the present study because we did not have access to individual level records from this country.

The study included all incident colorectal cancer cases diagnosed between 1961 and 2005 in Finland, Iceland, Norway and Sweden. Categories of ascending colon, transversal colon and descending colon were separated for specific analysis. All remaining parts of colon (e.g. sigmoid colon, appendix, cecum, splenic and hepatic flexures) were combined into "other colon" category.

Five controls for each case were randomly selected from the NOCCA cohort. Cases and controls could have a previous history of cancer other than colorectal cancer before the date of diagnosis of the case (hereafter "index date"). Cases and controls were matched by country, sex and year of birth. Study participants had to be 20 years or older at index date, and had to have at least one census record before that date.

Job history information of the study participants was obtained from computerized census records from 1960 and later censuses in Sweden and Norway, and from 1970 and later censuses in Finland. In Iceland, the only computerized census record was available from 1981 census. Census questionnaires were self-administered and included questions related to economic activity, occupation, and industry. In Finland, Norway, and Sweden they were filled in by the heads of households for all members of households, whereas in Iceland each member of household who was at least 17 years old, personally filled in the questionnaire [27].

Occupational benzene exposure was estimated by linking the NOCCA job-exposure matrix (NOCCA-JEM) to job titles of study participants. The NOCCA-JEM was developed by a Nordic expert panel, including experts from each of country based on the template of the Finnish job-exposure matrix (FINJEM) [28]. It assigns prevalence of exposure (P) and annual average level (L) of exposure among the exposed persons for 28 occupational agents in more than 300 specific occupational groups in four time periods: 1945-59, 1960-74, 1975-84, 1985-94 [29].

We assigned a product of $\mathrm{P}$ and $\mathrm{L}$ of benzene exposure to each year over the duration of employment period of study participants. These values were then summed up to estimate cumulative exposure to benzene. Employment period of study participants was assumed to start at age 20 years and end at either 65 years or index date, whichever occurred first. If a person had different occupations in different censuses, we assumed that he/she changed occupation midway of known census years. The same procedure was used to estimate cumulative exposures for co-exposures.

Selection of covariates for the main effect model was based on the "purposeful covariate selection" method [30]. All occupational agents considered as potential confounders, and significantly associated (Wald test $\mathrm{p}<0.25$ ) with colorectal cancer risk in univariate logistic regression models were selected for multivariate model. In the next step, covariates were removed from multivariate model if they were not significantly contributing to the model fit. This procedure suggested that formaldehyde, ionizing radiation, wood dust and perceived physical workload could be included into the final main effect model as covariates.

We estimated odds ratios (OR) and 95\% confidence intervals (CI) by using conditional logistic regression models. Cumulative benzene exposure and covariates were categorized by using $50^{\text {th }}$ and $90^{\text {th }}$ percentiles of exposure distribution among exposed controls as cut-points. Hence, the resulting exposure categories were: unexposed, $\leq 50$ th percentile, 50th-90th, $>$ 90th percentile. Unexposed categories were used as a reference in all analyses. We treated ordinal levels of benzene exposure as continuous in order to test for significance of dose-response relationship (p-trend). Significance of interaction between benzene exposure and sex were assessed by using analysis of variance.

Finally, we performed sensitivity analyses to evaluate robustness of the main findings. This included analysis with 10- and 20-year lag-time, analysis with tertile categorization and analysis with adjustment for lifestyle factors. The lag-time analyses were performed under the assumption that cancer may develop over a number of years, and recent exposures may not be related to the disease risk. Therefore, in 10 and 20 years lag-time analyses, we did not count exposures occurring 10 and 20 years before the index date, respectively. Because NOCCA-JEM assigns exposure values from 1945, we also conducted sensitivity analysis including only persons who spent most part of their working career after 1945. We therefore excluded persons born before 1920 in this sensitivity analysis.

Lifestyle related factors by occupation in Finland were available 
Table 1

Selected demographic characteristics of incident colorectal cancer cases in the Nordic Occupational Cancer Study (NOCCA) cohort during 1961-2005.

\begin{tabular}{|c|c|c|c|c|c|c|}
\hline \multirow[t]{3}{*}{ Characteristics } & \multicolumn{2}{|l|}{ Colon } & \multicolumn{2}{|l|}{ Rectum } & \multicolumn{2}{|l|}{ Colorectal } \\
\hline & $\begin{array}{l}\text { Cases } \\
(\mathrm{n}=181,709)\end{array}$ & $\begin{array}{l}\text { Controls } \\
(\mathrm{n}=908,545)\end{array}$ & $\begin{array}{l}\text { Cases } \\
(\mathrm{n}=109,227)\end{array}$ & $\begin{array}{l}\text { Controls } \\
(\mathrm{n}=546,135)\end{array}$ & $\begin{array}{l}\text { Cases } \\
(\mathrm{n}=290,936)\end{array}$ & $\begin{array}{l}\text { Controls } \\
(\mathrm{n}=1,454,680)\end{array}$ \\
\hline & n (\%) & n (\%) & n (\%) & n (\%) & n (\%) & n (\%) \\
\hline \multicolumn{7}{|l|}{ Country } \\
\hline Finland & $28,598(15.7)$ & $142,990(15.7)$ & $19,903(18.2)$ & $99,515(18.2)$ & $48,501(16.7)$ & 242,505 (16.7) \\
\hline Iceland & $1,116(0.6)$ & $5,580(0.6)$ & $424(0.4)$ & $2,120(0.4)$ & $1,540(0.5)$ & $7,700(0.5)$ \\
\hline Norway & $50,591(27.8)$ & $252,955(27.8)$ & $28,123(25.7)$ & $140,615(25.7)$ & $78,714(27.1)$ & $393,570(27.1)$ \\
\hline Sweden & $101,404(55.8)$ & $507,020(55.8)$ & $60,777(55.6)$ & $303,885(55.6)$ & $162,181(55.7)$ & 810,905 (55.7) \\
\hline \multicolumn{7}{|l|}{$\operatorname{Sex}$} \\
\hline Men & $85,037(46.8)$ & $425,185(46.8)$ & $60,019(54.9)$ & 300,095 (54.9) & $145,056(49.9)$ & $725,280(49.9)$ \\
\hline Women & $96,672(53.2)$ & $483,360(53.2)$ & $49,208(45.1)$ & $246,040(45.1)$ & $145,880(50.1)$ & $729,400(50.1)$ \\
\hline \multicolumn{7}{|l|}{ Age at diagnosis } \\
\hline$\leq 40$ & 2,757 (1.5) & 13,785 (1.5) & $984(0.9)$ & $4,944(0.9)$ & $3,741(1.3)$ & $18,729(1.3)$ \\
\hline $41-60$ & $33,378(18.4)$ & $166,890(18.4)$ & 21,713 (19.9) & 108,624 (19.9) & 55,091 (18.9) & $275,514(18.9)$ \\
\hline $61-80$ & $112,161(61.7)$ & $560,805(61.7)$ & $68,909(63.1)$ & $344,552(63.1)$ & $181,070(62.2)$ & $905,357(62.2)$ \\
\hline$\geq 80$ & $33,413(18.4)$ & $167,065(18.4)$ & $17,621(16.1)$ & $88,015(16.1)$ & $51,034(17.5)$ & $255,080(17.5)$ \\
\hline Mean (Median) & $70(71)$ & $70(71)$ & $69(70)$ & $69(70)$ & $70(71)$ & $70(71)$ \\
\hline \multicolumn{7}{|l|}{ Birth cohort } \\
\hline$\leq 1920$ & $106,357(58.5)$ & 531,785 (58.5) & $61,523(56.3)$ & $307,615(56.3)$ & $167,880(57.7)$ & $839,400(57.7)$ \\
\hline $1921-1930$ & $42,241(23.2)$ & $211,205(23.2)$ & $25,575(23.4)$ & $127,875(23.4)$ & $67,816(23.3)$ & $339,080(23.3)$ \\
\hline 1931-1940 & 20,599 (11.3) & $102,995(11.3)$ & $13,558(12.4)$ & $67,790(12.4)$ & 34,157 (11.7) & 170,785 (11.7) \\
\hline 1941-1950 & $10,112(5.6)$ & $50,560(5.6)$ & $7,046(6.5)$ & $35,230(6.5)$ & $17,158(5.9)$ & $85,790(5.9)$ \\
\hline $1951-1960$ & $2,400(1.3)$ & $12,000(1.3)$ & $1,525(1.4)$ & 7,625 (1.4) & $3,925(1.4)$ & 19,625 (1.4) \\
\hline
\end{tabular}

from FINJEM [28]. It provides data on proportions of daily smokers in each occupation, men drinking at least 8 and women drinking 5 portions of alcohol weekly, those who fulfill fewer than 3 of 4 recommended dietary habits, those who have leisure time exercise less than twice a week, and those whose body mass index is 25 or higher. Lifestyle related factors in FINJEM are based on data from large surveys conducted by the Finnish Public Health Institute [31]. Because these data cannot be directly used for other Nordic countries, we had to restrict analysis including lifestyle factors only to the Finnish part of the data.

All analyses were conducted by using $\mathrm{R}$ statistical software version 3.4.1.

\section{Results}

In total, the study included 181,709 all colon $(63,867$ ascending, 26,681 transversal, 8,863 descending, 82,298 "other colon"), 109,227 rectal, and 290,936 all colorectal cancer cases (Table 1). There were more female than male colon cancer cases, whereas rectum cancer was more common in males than females. Majority of the cases were from Sweden, while only less than $1 \%$ were from Iceland. The median age at diagnosis was 71 years for colon cancer, and 70 years for rectal cancer (Table 1).

Overall risk was statistically significantly elevated only for ascending colon (OR $=1.05,95 \%$ CI 1.01-1.10) (Table 2).

We observed significantly increased risk of colorectal cancer $(\mathrm{OR}=1.12,95 \% \mathrm{CI} 1.05-1.18)$ and colon cancer (OR $=1.15$, 95\% CI 1.07-1.23) for high cumulative benzene exposure category (Table 3). Colon cancer risk seemed to be restricted only to ascending ( $\mathrm{OR}=1.27$, 95\% CI 1.13-1.43) and transversal types (OR $=1.21,95 \%$ CI 1.01-1.41). The risk of rectal cancer was slightly elevated for medium benzene exposure (OR $=1.06,95 \%$ CI 1.01-1.11) but not for high exposure level. Significant dose-response relationships were observed between benzene exposure and all colorectal, all colon, and ascending colon cancer (Table 3 ).

High level of cumulative benzene exposure was linked to an increased risk of colorectal cancer both in men (OR $=1.10$, 95\% CI 1.03-1.17) and women ( $\mathrm{OR}=1.60,95 \%$ CI 1.24-2.07) (Table 4).
Table 2

Odds ratios (OR) and 95\% confidence intervals (95\% CI) for ever vs never benzene exposure and colorectal cancer.

\begin{tabular}{|c|c|c|c|c|c|}
\hline $\begin{array}{l}\text { Cancer location } \\
\text { Benzene }\end{array}$ & Case, $n$ & Control, $n$ & $\mathrm{OR}^{\mathrm{a}}$ & $95 \% \mathrm{CI}$ & p-value \\
\hline \multicolumn{6}{|l|}{ Ascending colon } \\
\hline Never & 60720 & 304382 & 1.00 & & \\
\hline Ever & 3147 & 14953 & 1.05 & $1.01-1.10$ & 0.02 \\
\hline \multicolumn{6}{|c|}{ Transversal colon } \\
\hline Never & 25338 & 126653 & 1.00 & & \\
\hline Ever & 1343 & 6752 & 1.00 & $0.93-1.06$ & 0.89 \\
\hline \multicolumn{6}{|c|}{ Descending colon } \\
\hline Never & 8403 & 42070 & 1.00 & & \\
\hline Ever & 460 & 2245 & 1.03 & $0.92-1.15$ & 0.59 \\
\hline \multicolumn{6}{|l|}{ Other colon } \\
\hline Never & 78019 & 390233 & 1.00 & & \\
\hline Ever & 4279 & 21257 & 1.01 & $0.98-1.05$ & 0.54 \\
\hline \multicolumn{6}{|l|}{ All colon } \\
\hline Never & 172480 & 863338 & 1.00 & & \\
\hline Ever & 9229 & 45207 & 1.02 & $1.00-1.05$ & 0.06 \\
\hline \multicolumn{6}{|l|}{ Rectum } \\
\hline Never & 103071 & 515805 & 1.00 & & \\
\hline Ever & 6156 & 30330 & 1.01 & $0.98-1.04$ & 0.75 \\
\hline \multicolumn{6}{|l|}{ All colorectal } \\
\hline Never & 275551 & 1379143 & 1.00 & & \\
\hline Ever & 15385 & 75537 & 1.02 & $1.00-1.04$ & 0.09 \\
\hline
\end{tabular}

a OR estimates for benzene were adjusted for perceived physical workload, formaldehyde, ionizing radiation, and wood dust.

Similarly, all colon and ascending colon cancer risks were increased in both sexes. The risk of transversal colon cancer for high benzene exposure was significantly increased only in men (OR $=1.21,95 \% \mathrm{CI}$ $1.01-1.46)$ and non-significantly increased in women (OR $=1.37,95 \%$ CI 0.55-3.42). The risk of "other colon" cancer was linked to high benzene exposure in women (OR $=1.83,95 \%$ CI 1.16-2.88) but not in men. High benzene exposure was associated to cancer of rectum in women $(\mathrm{OR}=1.57,95 \% \mathrm{CI} 1.01-2.42)$, and medium exposure in men $(\mathrm{OR}=1.05,95 \%$ CI 1.00-1.11) (Table 4). Sex-specific differences of 
Table 3

Odds ratios (OR) and 95\% confidence intervals (95\% CI) for occupational benzene exposure and colorectal cancer. Benzene was categorized based on 50th and 90th percentile of cumulative exposure distribution among exposed colorectal cancer cases and controls.

\begin{tabular}{|c|c|c|c|c|c|}
\hline $\begin{array}{l}\text { Cancer location } \\
\text { Benzene }{ }^{\mathrm{a}, \mathrm{b}}\end{array}$ & Case, $n$ & Control, $n$ & $\mathrm{OR}^{\mathrm{c}}$ & $95 \%$ CI & $\mathrm{p}$-trend \\
\hline $\begin{array}{l}\text { Ascending colon } \\
\text { unexposed }\end{array}$ & 60720 & 304382 & 1.00 & & \\
\hline Low & 1546 & 7476 & 1.04 & $0.99-1.10$ & \\
\hline medium & 1231 & 6038 & 1.00 & $0.94-1.08$ & \\
\hline High & 370 & 1439 & 1.27 & $1.13-1.43$ & $<0.01$ \\
\hline $\begin{array}{l}\text { Transversal colo } \\
\text { unexposed }\end{array}$ & 25338 & 126653 & 1.00 & & \\
\hline Low & 679 & 3452 & 0.99 & $0.91-1.08$ & \\
\hline medium & 513 & 2677 & 0.94 & $0.85-1.05$ & \\
\hline High & 151 & 623 & 1.21 & $1.01-1.44$ & 0.74 \\
\hline $\begin{array}{l}\text { Descending colo } \\
\text { unexposed }\end{array}$ & 8403 & 42070 & 1.00 & & \\
\hline Low & 219 & 1139 & 0.98 & $0.85-1.14$ & \\
\hline medium & 200 & 884 & 1.14 & $0.96-1.36$ & \\
\hline High & 41 & 222 & 0.90 & $0.64-1.26$ & 0.53 \\
\hline $\begin{array}{l}\text { Other colon } \\
\text { unexposed }\end{array}$ & 78019 & 390233 & 1.00 & & \\
\hline Low & 2094 & 10617 & 1.00 & $0.95-1.05$ & \\
\hline medium & 1721 & 8507 & 1.02 & $0.96-1.08$ & \\
\hline High & 464 & 2133 & 1.07 & $0.96-1.18$ & 0.29 \\
\hline $\begin{array}{l}\text { All colon } \\
\text { unexposed }\end{array}$ & 172480 & 863338 & 1.00 & & \\
\hline Low & 4538 & 22684 & 1.01 & $0.98-1.04$ & \\
\hline medium & 3665 & 18106 & 1.01 & $0.97-1.05$ & \\
\hline High & 1026 & 4417 & 1.15 & $1.07-1.23$ & 0.01 \\
\hline $\begin{array}{l}\text { Rectum } \\
\text { unexposed }\end{array}$ & 103071 & 515805 & 1.00 & & \\
\hline Low & 3169 & 16298 & 0.97 & $0.93-1.01$ & \\
\hline medium & 2606 & 12173 & 1.06 & $1.01-1.11$ & \\
\hline High & 381 & 1859 & 1.03 & $0.92-1.15$ & 0.18 \\
\hline $\begin{array}{l}\text { All colorectal } \\
\text { unexposed }\end{array}$ & 275551 & 1379143 & 1.00 & & \\
\hline Low & 8051 & 40671 & 0.99 & $0.97-1.02$ & \\
\hline medium & 5960 & 28741 & 1.03 & 0.99-1.06 & \\
\hline High & 1374 & 6125 & 1.12 & $1.05-1.18$ & $<0.01$ \\
\hline
\end{tabular}

${ }^{\text {a }}$ Low benzene exposure category was defined as $\leq 4.3$ parts per million (ppm)-years; medium category 4.3-10.5 ppm-years; high category $>10.5$ ppmyears.

b Unexposed category was used as reference in all analyses.

c OR estimates for benzene were adjusted for perceived physical workload, formaldehyde, ionizing radiation, and wood dust.

odds ratios were statistically significant for all colorectal cancer ( $\mathrm{p}<0.01$ ), all colon $(\mathrm{p}<0.01)$, ascending colon $(\mathrm{p}<0.01)$, and rectal cancer $(\mathrm{p}=0.04)$, but not for "other colon" ( $\mathrm{p}=0.17)$ and transversal colon $(\mathrm{p}=0.09)$.

The odds ratios for all colorectal, all colon, and ascending colon cancers remained significantly increased in 10- and 20-year lag-time analyses (Supplementary Table 1). The risk of transversal cancer was significantly increased only in 10 -year lag-time analysis $(\mathrm{OR}=1.25$, 95\% CI 1.03-1.52).

In an analysis with tertile categorization, high benzene exposure was associated to an increased risk of all colorectal (OR $=1.06,95 \% \mathrm{CI}$ 1.03-1.09), all colon (OR $=1.08,95 \%$ CI 1.03-1.12), ascending colon $(\mathrm{OR}=1.12,95 \%$ CI 1.04-1.19), and "other colon" cancer $(\mathrm{OR}=1.07$, 95\% CI 1.01-1.14) (Supplementary Table 2).

In a sensitivity analysis based on Finnish data only, inclusion of lifestyle related factors into the model seemed to slightly reduce odds ratios towards null. However, the difference between adjusted and unadjusted for lifestyle factors odds ratios were small, i.e. in the order of 0.05 (Supplementary Table 3).
The main results did not change considerably when persons born before 1920 were excluded from the analysis (Supplementary Table 4).

\section{Discussion}

The present study demonstrates positive associations between benzene exposure and colorectal cancer risk. The risk was most evident for ascending and transversal colon, and these associations were stronger in women than men. High benzene exposure seemed to increase the risk of rectal cancer only among women. The odds ratios for colorectal and colon cancers remained significantly elevated also in sensitivity analyses where adjustments for potential fife-style factor were included.

The results of the present study suggest variation of colorectal cancer risk by sex and cancer location. Sex-specific differences of odds ratios were statistically significant, and colon cancer risk seemed to be restricted to the proximal colon (ascending and transversal). We do not know the reason for variation of the effect of benzene exposure, which has not been investigated thoroughly before. Some previous studies have also observed variation of colorectal cancer risk by cancer location and sex, though not for benzene but for physical activity and asbestos exposure $[15,17,19,32]$.

One of the advantages of the present study is the accuracy and completeness of cancer incidence data. Validation studies showed high degree of completeness, comparability, accuracy and timeliness of cancer registration in the Nordic countries [33].

Accurate data on job titles from census records is another methodological strength of the study. Previous validity studies demonstrated high accuracy of occupational classifications based on census records in the Nordic countries [34,35]. By linking job histories to NOCCA-JEM, we were able to control for the effect of many concomitant agents that can be present among benzene exposed workers.

Potential exposure misclassification is the main limitation of the study. First, the NOCCA-JEM cannot account for exposure variation within the occupation, because it assigns average exposure to all members of the occupational group. Second, the NOCCA-JEM does not specify occupations by industrial groups. Exposure intensity and prevalence may vary by industries included into the same occupation. Third, we did not have complete job histories of study participants, and therefore, imputed them from available computerized census records by assuming a person changed occupation midway between consecutive censuses. Job histories were imputed from four census records for the persons from Sweden, and from three census records for the persons from Finland and Norway. Swedish population corresponded to $55.7 \%$, Finnish and Norwegian populations to $43.8 \%$ of total study population. In Iceland, the only available computerized census record was 1981 census. However, this is unlikely to strongly bias the main results, because Icelandic population constituted less than $1 \%$ of overall study population (Table 1). In addition, previous studies demonstrated low occupational mobility in the Nordic countries [27,34].

We used the same exposure estimation method for cases and controls in this study. Therefore, exposure estimation was independent of disease status of study participants, and exposure misclassification was likely to be non-differential. Bias from non-differential exposure is generally towards the null for dichotomous exposures [36]. When exposure has more than two categories, biases away from the null occur only for intermediate exposure categories, but misclassified odds ratio for the highest category will be towards the null [37]. Therefore, overall odds ratios from Table 2 and odds ratios for the high benzene exposure category from Table 3 are likely to be underestimated, and the true risk estimates are likely to be higher.

We could not control for leisure time physical activity, diet, smoking, alcohol intake, and body mass index in the main analyses. These factors have been linked to colorectal cancer risk in previous studies [10-14]. However, we were able to assess on aggregate level the effect of lifestyle factors on associations between benzene and colorectal cancer in the Finnish part of the data. In this sensitivity analysis, 
Table 4

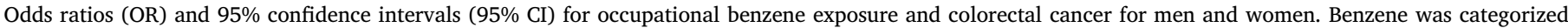
based on 50th and 90th percentile of cumulative exposure distribution among exposed colorectal cancer cases and controls.

\begin{tabular}{|c|c|c|c|c|c|c|c|c|c|c|}
\hline \multirow{2}{*}{$\begin{array}{l}\text { Cancer location } \\
\text { Benzene }^{\mathrm{a}, \mathrm{b}}\end{array}$} & \multicolumn{5}{|l|}{ Men } & \multicolumn{5}{|l|}{ Women } \\
\hline & Case, $n$ & Control, $n$ & $\mathrm{OR}^{\mathrm{c}}$ & $95 \% \mathrm{CI}$ & p-trend & Case, $n$ & Control, $n$ & $\mathrm{OR}^{\mathrm{c}}$ & $95 \% \mathrm{CI}$ & p-trend \\
\hline \multicolumn{11}{|l|}{ Ascending colon } \\
\hline Unexposed & 25245 & 126775 & 1.00 & & & 35475 & 177607 & 1.00 & & \\
\hline Low & 1040 & 5080 & 1.04 & $0.97-1.12$ & & 506 & 2396 & 1.06 & $0.96-1.17$ & \\
\hline Medium & 1088 & 5374 & 1.01 & $0.94-1.09$ & & 143 & 664 & 1.07 & $0.89-1.28$ & \\
\hline High & 348 & 1376 & 1.28 & $1.13-1.44$ & $<0.01$ & 22 & 63 & 1.75 & $1.07-2.87$ & 0.04 \\
\hline \multicolumn{11}{|c|}{ Transversal colon } \\
\hline Unexposed & 11436 & 57316 & 1.00 & & & 13902 & 69337 & 1.00 & & \\
\hline Low & 509 & 2466 & 1.05 & $0.95-1.16$ & & 170 & 986 & 0.87 & $0.73-1.02$ & \\
\hline Medium & 466 & 2399 & 0.96 & $0.86-1.08$ & & 47 & 278 & 0.85 & $0.62-1.16$ & \\
\hline High & 145 & 599 & 1.21 & $1.01-1.46$ & 0.29 & 6 & 24 & 1.37 & $0.55-3.42$ & 0.11 \\
\hline \multicolumn{11}{|c|}{ Descending colon } \\
\hline Unexposed & 3972 & 19948 & 1.00 & & & 4431 & 22122 & 1.00 & & \\
\hline Low & 167 & 821 & 1.05 & $0.88-1.26$ & & 52 & 318 & 0.84 & $0.62-1.13$ & \\
\hline Medium & 178 & 807 & 1.14 & $0.94-1.37$ & & 22 & 77 & 1.48 & $0.92-2.39$ & \\
\hline High & 41 & 214 & 0.96 & $0.68-1.35$ & 0.35 & 0 & 8 & - & - & 0.97 \\
\hline \multicolumn{11}{|l|}{ Other colon } \\
\hline Unexposed & 36840 & 184531 & 1.00 & & & 41179 & 205702 & 1.00 & & \\
\hline Low & 1560 & 7632 & 1.04 & $0.98-1.10$ & & 534 & 2985 & 0.91 & 0.83-0.99 & \\
\hline Medium & 1564 & 7787 & 1.02 & 0.96-1.09 & & 157 & 720 & 1.09 & $0.92-1.30$ & \\
\hline High & 438 & 2060 & 1.05 & $0.95-1.17$ & 0.16 & 26 & 73 & 1.83 & $1.16-2.88$ & 0.83 \\
\hline \multicolumn{11}{|l|}{ All colon } \\
\hline Unexposed & 77493 & 388570 & 1.00 & & & 94987 & 474768 & 1.00 & & \\
\hline Low & 3276 & 15999 & 1.04 & $1.00-1.08$ & & 1262 & 6685 & 0.95 & $0.90-1.01$ & \\
\hline Medium & 3296 & 16367 & 1.02 & $0.97-1.06$ & & 369 & 1739 & 1.06 & $0.95-1.19$ & \\
\hline High & 972 & 4249 & 1.14 & $1.06-1.23$ & $<0.01$ & 54 & 168 & 1.64 & $1.20-2.24$ & 0.46 \\
\hline \multicolumn{11}{|l|}{ Rectum } \\
\hline Unexposed & 54758 & 274370 & 1.00 & & & 48313 & 241435 & 1.00 & & \\
\hline Low & 2443 & 12567 & 0.96 & $0.91-1.00$ & & 726 & 3731 & 0.98 & $0.91-1.07$ & \\
\hline Medium & 2464 & 11394 & 1.05 & $1.00-1.11$ & & 142 & 779 & 0.92 & $0.77-1.10$ & \\
\hline High & 354 & 1764 & 0.99 & $0.89-1.12$ & 0.36 & 27 & 95 & 1.57 & $1.01-2.42$ & 0.88 \\
\hline \multicolumn{11}{|l|}{ All colorectal } \\
\hline Unexposed & 132251 & 662940 & 1.00 & & & 143300 & 716203 & 1.00 & & \\
\hline Low & 5948 & 29661 & 1.01 & $0.98-1.04$ & & 2103 & 11010 & 0.97 & $0.92-1.01$ & \\
\hline Medium & 5563 & 26815 & 1.04 & $1.00-1.07$ & & 397 & 1926 & 1.04 & $0.93-1.16$ & \\
\hline High & 1294 & 5864 & 1.10 & $1.03-1.17$ & $<0.01$ & 80 & 261 & 1.60 & $1.24-2.07$ & 0.55 \\
\hline
\end{tabular}

${ }^{\text {a }}$ Low benzene exposure category was defined as $\leq 4.3$ ppm (ppm)-years; medium category $4.3-10.5$ ppm-years; high category $>10.5$ ppm-years.

b Unexposed category was used as reference in all analyses.

c OR estimates for benzene were adjusted for perceived physical workload, formaldehyde, ionizing radiation, and wood dust.

adjustment for lifestyle factors slightly attenuated odds ratio estimates towards the null. Therefore, assuming that similar reductions in odds ratios would be observed in an analysis of the entire study population, if data on lifestyle factors were available, most of the associations observed in this study would likely remain.

Occupational groups contributing to the highest benzene exposure category in NOCCA-JEM are shown in Table 5. Some of these benzeneexposed occupational groups have been linked to an increased colorectal cancer risk in previous studies. In a systematic review and metaanalysis [38], significantly increased risk of colorectal cancers was reported for workers in the manufacture of leather and leather products (relative risk $(\mathrm{RR})=1.70,95 \%$ CI $1.24-2.34$ ), machinery and equipment ( $R R=2.20,95 \%$ CI 1.03-4.72), repair and installation of machinery equipment $(\mathrm{RR}=1.40,95 \%$ CI $1.07-1.84)$. The incidence of colon cancer was increased for printing workers $(\mathrm{RR}=1.80,95 \% \mathrm{CI}$ $1.20-2.70$ ), rubber and plastic product workers ( $R R=1.19,95 \% \mathrm{CI}$ $1.00-1.42)$, repair and installation of machinery workers $(R R=1.75$, 95\% CI 1.27-2.41). The risk of rectal cancer was increased in the manufacture of coke and refined petroleum products $(\mathrm{RR}=2.49,95 \%$ CI 1.02-6.07) [38]. Our results are also consistent with results from the study by Goldberg et al [25], which observed an association between colon cancer and substantial benzene exposure (OR $=1.9,95 \%$ CI 1.1-3.3).
Table 5

Occupations with the highest probability (P) and annual average (L) benzene exposure in 1945-59, 1960-74, 1975-84, 1985-94. Estimates were retrieved from the Nordic Occupational Cancer Study (NOCCA) job-exposure matrix for Finland.

\begin{tabular}{lllll}
\hline Occupation $^{\mathrm{a}}$ & $1945-59$ & $1960-74$ & $1975-84$ & $1985-94$ \\
\cline { 2 - 5 } & $(\mathrm{P} \times \mathrm{L})^{\mathrm{b}}$ & $(\mathrm{P} \times \mathrm{L})^{\mathrm{b}}$ & $(\mathrm{P} \times \mathrm{L})^{\mathrm{b}}$ & $\left.{ }^{(\mathrm{P} \times \mathrm{L}}\right)^{\mathrm{b}}$ \\
\hline $\begin{array}{l}\text { Cookers and furnacemen (chemical } \\
\quad \text { processes) }\end{array}$ & 0.30 & 0.10 & 0.10 & 0.01 \\
$\begin{array}{l}\text { Footwear workers } \\
\text { Laboratory assistants }\end{array}$ & 2.50 & 1.50 & 0.00 & 0.00 \\
Lasters and sole fitters & 0.30 & 0.20 & 0.05 & 0.00 \\
Machine and engine mechanics & 10.00 & 3.00 & 0.00 & 0.00 \\
Occupation in graphics & 0.40 & 0.30 & 0.02 & 0.01 \\
Painters, lacquerers and floor layers & 0.60 & 0.20 & 0.00 & 0.00 \\
Printers & 0.40 & 0.10 & 0.00 & 0.00 \\
Refinery workers, other workers in the & 0.60 & 0.30 & 0.00 & 0.00 \\
$\quad$ chemical industry & & 0.10 & 0.05 & 0.00 \\
Rubber product workers & 0.30 & 0.20 & 0.00 & 0.00 \\
Service station attendants & 0.80 & 0.80 & 0.06 & 0.00 \\
Upholsterers & 1.00 & 0.20 & 0.00 & 0.00
\end{tabular}

a Occupations are listed in alphabetical order.

${ }^{\mathrm{b}}$ Unit of exposure is parts per million (ppm). 
In conclusion, this study showed increased risk of colorectal cancer associated with occupational benzene exposure. The risk of colon cancer was restricted to proximal (ascending and transversal) but not distal colon. Benzene exposure was also related to increased risk of rectal cancer in women only, but without a dose-response pattern.

\section{Authorship contribution statement}

Each author mentioned in the list of authors has contributed to the study planning, data collection, statistical analysis, interpretation of the results, and development of the manuscript

\section{Ethical approval}

As this study was register-based, neither ethical committee review nor informed consent from the study subjects was required.

\section{Funding}

This research did not receive any specific grant from funding agencies in the public, commercial, or not-for-profit sectors.

\section{Conflict of interest}

None.

\section{Acknowledgment}

We thank the Nordic Occupational Cancer Studies (NOCCA) project members for the development of NOCCA cohort data and job-exposure matrix.

\section{Appendix A. Supplementary data}

Supplementary material related to this article can be found, in the online version, at doi:https://doi.org/10.1016/j.canep.2018.06.011.

\section{References}

[1] R. Nordlinder, O. Ramnäs, Exposure to benzene at different workplaces in Sweden, Ann. Occup. Hyg. 31 (1987) 345-355.

[2] International Agency for Research on Cancer, Chemicals and industrial processes associated with cancer in humans: an updating of IARC monographs volumes 1 to 20, IARC Monogr. Eval. Carcinog. Risks Hum. (suppl) (1979) 1-15.

[3] International Agency for Research on Cancer, A review of human carcinogens part F: chemical agents and related occupations, IARC Monogr. Eval. Carcinog. Risks Hum. 100F (2012) 249-294.

[4] D. Loomis, K.Z. Guyton, Y. Grosse, et al., Carcinogenicity of benzene, Lancet Oncol. 18 (12) (2017) 1574-1575, http://dx.doi.org/10.1016/S1470-2045(17)30832-X [published Online First: 26 October 2017].

[5] M.S. Linet, S.N. Yin, E.S. Gilbert, et al., A retrospective cohort study of cause-specific mortality and incidence of hematopoietic malignancies in Chinese benzeneexposed workers, Int. J. Cancer 137 (9) (2015) 2184-2197, http://dx.doi.org/10 1002/ijc.29591 [published Online First: 16 June 2015].

[6] A.R. Schnatter, D.C. Glass, G. Tang, et al., Myelodysplastic syndrome and benzene exposure among petroleum workers: an international pooled analysis, J. Natl. Cancer Inst. 104 (22) (2012) 1724-1737, http://dx.doi.org/10.1093/jnci/djs411 [published Online First: 30 October 2012].

[7] J.S. Stenehjem, K. Kjaerheim, M. Bratveit, et al., Benzene exposure and risk of lymphohaematopoietic cancers in 25000 offshore oil industry workers, Br. J. Cancer 112 (9) (2015) 1603-1612, http://dx.doi.org/10.1038/bjc.2015.108.

[8] J. Ferlay, I. Soerjomataram, M. Ervik, et al., GLOBOCAN 2012 v1.0, Cancer Incidence and Mortality Worldwide: IARC CancerBase No. 11, [Internet] International Agency for Research on Cancer, Lyon, France, 2013 Available from: http://globocan.iarc.fr (accessed 4 November 2017).

[9] G. Engholm, J. Ferlay, N. Christensen, et al., NORDCAN: Cancer Incidence, Mortality, Prevalence and Survival in the Nordic Countries, Version 7.3. Available from: Association of the Nordic Cancer Registries. Danish Cancer Society, 2016 (accessed 7 November 2017), http://www.ancr.nu.

[10] D. Aune, D.S. Chan, A.R. Vieira, et al., Red and processed meat intake and risk of colorectal adenomas: a systematic review and meta-analysis of epidemiological studies, Cancer Cause Control 24 (4) (2013) 611-627, http://dx.doi.org/10.1007/ s10552-012-0139-Z.

[11] P.S. Liang, T.Y. Chen, E. Giovannucci, Cigarette smoking and colorectal cancer incidence and mortality: systematic review and meta-analysis, Int. J. Cancer 124 (10) (2009) 2406-2415, http://dx.doi.org/10.1002/ijc.24191.

[12] P.S. Perera, R.L. Thompson, M.J. Wiseman, Recent evidence for colorectal cancer prevention through healthy food, nutrition, and physical activity: implications for recommendations, Curr. Nutr. Rep. 1 (1) (2012) 44-54, http://dx.doi.org/10.1007/ s13668-011-0006-7.

[13] S. Schlesinger, K. Aleksandrova, L. Abar, et al., Adult weight gain and colorectal adenomas - a systematic review and meta-analysis, Ann. Oncol. 28 (6) (2017) 1217-1229, http://dx.doi.org/10.1093/annonc/mdx080.

[14] A.R. Vieira, L. Abar, D.S.M. Chan, et al., Foods and beverages and colorectal cancer risk: a systematic review and meta-analysis of cohort studies, an update of the evidence of the WCRF-AICR continuous update project, Ann. Oncol. 28 (8) (2017) 1788-1802, http://dx.doi.org/10.1093/annonc/mdx171.

[15] K. Isomura, S. Kono, M.A. Moore, et al., Physical activity and colorectal cancer: the Fukuoka colorectal cancer study, Cancer Sci. 97 (10) (2006) 1099-1104, http://dx. doi.org/10.1111/j.1349-7006.2006.00282.x.

[16] T.I. Nilsen, P.R. Romundstad, H. Petersen, et al., Recreational physical activity and cancer risk in subsites of the colon (the nord-trondelag health study), Cancer Epidemiol. Biomarkers Prev. 17 (1) (2008) 183-188, http://dx.doi.org/10.1158/ 1055-9965.EPI-07-0746.

[17] J. Sormunen, M. Talibov, J.I. Martinsen, et al., Perceived physical strain at work and incidence of colorectal cancer: a nested case-control study, Cancer Epidemiol. 43 (2016) 100-104, http://dx.doi.org/10.1016/j.canep.2016.07.001.

[18] L. Kachuri, P.J. Villeneuve, M.E. Parent, et al., Workplace exposure to diesel and gasoline engine exhausts and the risk of colorectal cancer in Canadian men, Environ. Health 15 (2016) 4, http://dx.doi.org/10.1186/s12940-016-0088-1.

[19] N.S.M. Offermans, R. Vermeulen, A. Burdorf, et al., Occupational asbestos exposure and risk of esophageal, gastric and colorectal cancer in the prospective Netherlands cohort study, Int. J. Cancer 135 (8) (2014) 1970-1977, http://dx.doi.org/10.1002/ ijc. 28817.

[20] X. Wang, A. Ji, Y. Zhu, et al., A meta-analysis including dose-response relationship between night shift work and the risk of colorectal cancer, Oncotarget 6 (28) (2015) 25046-25060, http://dx.doi.org/10.18632/oncotarget.4502.

[21] G. Arbman, O. Axelson, M. Fredriksson, et al., Do occupational factors influence the risk of colon and rectal cancer in different ways? Cancer 72 (9) (1993) 2543-2549.

[22] S. Dumas, M.E. Parent, J. Siemiatycki, et al., Rectal cancer and occupational risk factors: a hypothesis-generating, exposure-based case-control study, Int. J. Cancer 87 (6) (2000) 874-879.

[23] S. El-Zaemey, T.N. Anand, J.S. Heyworth, et al., Case-control study to assess the association between colorectal cancer and selected occupational agents using INTEROCC job exposure matrix, Occup. Environ. Med. 75 (2018) 290-295.

[24] L. Kaerlev, J. Hansen, H.L. Hansen, et al., Cancer incidence among Danish seafarers: a population based cohort study, Occup. Environ. Med. 62 (2005) 761-765, http:// dx.doi.org/10.1136/oem.2005.020818.

[25] M.S. Goldberg, M.E. Parent, J. Siemiatycki, et al., A case-control study of the relationship between the risk of colon cancer in men and exposures to occupational agents, Am. J. Ind. Med. 39 (6) (2001) 531-546.

[26] M. Gerin, J. Siemiatycki, M. Desy, et al., Associations between several sites of cancer and occupational exposure to benzene, toluene, xylene, and styrene: results of a case-control study in Montreal, Am. J. Ind. Med. 34 (2) (1998) 144-156.

[27] E. Pukkala, J.I. Martinsen, E. Lynge, et al., Occupation and cancer - follow-up of 15 million people in five Nordic countries, Acta Oncol. 48 (5) (2009) 646-790, http:// dx.doi.org/10.1080/02841860902913546.

[28] T. Kauppinen, J. Toikkanen, E. Pukkala, From cross-tabulations to multipurpose exposure information systems: a new job-exposure matrix, Am. J. Ind. Med. 33 (4) (1998) 409-417.

[29] T. Kauppinen, P. Heikkilä, N. Plato, et al., Construction of job-exposure matrices for the Nordic occupational cancer study (NOCCA), Acta Oncol. 48 (5) (2009) 791-800, http://dx.doi.org/10.1080/02841860902718747.

[30] D. Hosmer, S. Lemeshow, Applied Logistic Regression, 2nd ed., John Willey \& Sons, New York, US, 2004.

[31] Terveyden ja hyvinvoinnin laitos (THL), Suomalaisen aikuisväestön terveyskäyttäytyminen ja terveys, kevät 2014, Raportti 6/2015. [National Institute for health and Welfare (THL). health behavior and health among the Finnish adult population, Spring 2014], Available from: Juvenes Print - Suomen Yliopistopaino Oy, Tampere, 2015 (accessed on 17 November 2017), http://www.julkari.fi/ bitstream/handle/10024/126023/URN_ISBN_978-952-302-447-2.pdf? sequence $=1$.

[32] I. Thune, E. Lund, Physical activity and risk of colorectal cancer in men and women, Br J Cancer 73 (9) (1996) 1134-1140.

[33] E. Pukkala, G. Engholm, L.K. Højsgaard Schmidt, et al., Similarities and differences of the Nordic cancer registries - an overview of their procedures and data comparability, Acta Oncol. 57 (2018) 440-455.

[34] R. Kolari, Occupational Mortality in Finland 1975/1980/1985, Statistics Finland, Helsinki (Finland), 1989.

[35] Folke- og boligtelling, Kontrollundersokelse [Population and Housing census 1970. Evaluation Survey Vol 6 Statistisk Sentralbyrå [Statistics Norway], Oslo, Norway, 1970.

[36] K.J. Rothman, S. Greenland, T.L. Lash, Modern Epidemiology, $3^{\text {rd }}$ edition, Lippincott \& Williams, 2008.

[37] N.J. Birkett, Effect of nondifferential misclassification of estimates of odds ratios with multiple levels of exposure, Am. J. Epidemiol. 136 (1992) 356-362.

[38] E. Oddone, C. Modonesi, G. Gatta, Occupational exposures and colorectal cancers: a quantitative overview of epidemiological evidence, World J. Gastroenterol. 20 (35) (2014) 12431-12444, http://dx.doi.org/10.3748/wjg.v20.i35.12431. 